\title{
Development and initial testing of the self-care of chronic illness inventory 慢性病自我护理量表的制定和初步测试
}

Barbara Riegel, Claudio Barbaranelli, Kristen A. Sethares, Marguerite Daus, Debra K. Moser, Jennifer L. Miller, Christine A. Haedtke, Jodi L. Feinberg, Solim Lee, Anna Stromberg, Tiny Jaarsma

\begin{abstract}
Background: Existing measures of self-care are disease-specific or behavior-specific; no theorydriven generic measure of self-care exists. The purpose of this study was to test the psychometric properties of the Self-Care of Chronic Illness Inventory (SC-CII or "Sky").

Methods: We developed a 20-item self-report instrument based on the Middle Range Theory of Self-Care of Chronic Illness, with three separate scales measuring Self-Care Maintenance, SelfCare Monitoring and Self-Care Management. Each of the three scales is scored separately and standardized 0 to 100 with higher scores indicating better self-care. After demonstrating content validity, psychometric testing was conducted in a convenience sample of 407 adults (63 \pm 15 years, 54\% male, $2.7 \pm 1.3$ chronic conditions) enrolled from in-patient and out-patient settings at five sites in the United States and ResearchMatch.org. Dimensionality testing with confirmatory factor analysis preceded reliability testing.
\end{abstract}

Results: Self-Care Maintenance scale (8 items, 2 factors: illness related and health promoting behavior) fit well when tested with a two-factor confirmatory model. Internal coherence reliability was .67. Self-Care Monitoring scale (5 items, single factor) fit well and reliability was 81. Self-Care Management scale (7 items, 2 factors: autonomous and consulting behavior), when tested with a two-factor confirmatory model, fit adequately. Internal coherence reliability was .71. A simultaneous confirmatory factor analysis on the combined set of items supported this more general model.

Conclusions: The SC-CII is adequate in reliability and validity. We suggest further testing in diverse populations of patients with chronic illnesses. 
$\underline{\text { Key words: }}$ self-care, psychometrics, chronic disease, multimorbidity, comorbidity, validity, factor analysis 


\section{Background}

During the last century, improvements in public health and innovations in health care have dramatically increased life expectancy worldwide. With an aging population, a majority of individuals report chronic illness and 38 million deaths are due to chronic illness annually [1]. Chronic illnesses are usually permanent or recurrent, significantly affect physical or emotional well-being, require daily and consistent health care management, and last more than three months [2]. With chronic illness now the largest health threat and the primary driver of health care costs worldwide, researchers, health care providers, and health care systems are focusing on interventions that can prevent or control exacerbations. For this reason, the importance of selfcare is increasingly recognized. No theory-based instrument is available to measure the process of self-care used by individuals with a variety of chronic conditions. The purpose of this study was to test the content validity, reliability, and construct validity of the Self-Care of Chronic Illness Inventory (SC-CII or “Sky”).

\section{Theoretical Framework}

The SC-CII was developed based on the Middle Range Theory of Self-Care of Chronic Illness, which describes self-care as a naturalistic decision-making process involving health promoting practices and illness management [3]. We note that the terms self-care and self-management are often used as synonyms, but we use self-care as the overarching term, capturing management as one element of the general self-care process. Self-care is performed in both healthy and ill states. When one has a chronic illness, self-care addresses the behavioral requirements to maintain stability and control symptoms. Three key concepts are included in the theory: Self-Care Maintenance, Self-Care Monitoring, and Self-Care Management. Self-Care Maintenance refers to those behaviors used by persons with a chronic illness to maintain physical and emotional stability. These health promoting behaviors (e.g. smoking cessation, preparing healthy food, 
coping with stress) or illness-related behaviors (e.g. taking medication as prescribed) are used to maintain stability and prevent an exacerbation [4]. Self-Care Monitoring refers to the process of observing oneself for changes in signs and symptoms (e.g., body listening). These behaviors are needed for early detection of a health change. Self-Care Management is the response to signs and symptoms when they occur. These behaviors can be done autonomously or in consultation with a health care provider, depending on the messages the patient is given by the provider about independent modifications of therapies [4]. Once a change in signs and/or symptoms is identified, Self-Care Management is required to control the situation before it escalates and requires urgent or emergent care. We designed the SC-CII to capture this process with three separate scales: Self-Care Maintenance, Self-Care Monitoring, and Self-Care Management.

\section{Importance of Self-Care}

Self-care is the primary means of caring for a chronic condition. It is estimated that $>99 \%$ of the day-to-day care for chronic illness is performed by the person who is ill and family caregivers; healthcare providers have only a peripheral role mainly during crises requiring acute care [5]. During these illness events, care often occurs in silos, with medical treatments, education, and support for self-care targeting a single condition. Yet many people, especially those who are elderly, suffer from multimorbidity with two or more chronic illnesses coexisting. Six in 10 adults in the U.S. live with at least one chronic illness,[6] and multimorbidity ( $\geq 2$ chronic conditions) increases with age.[7, 8] The unique challenges faced by persons with multimorbidity are often overlooked with a silo approach to health care.

Many of the self-care behaviors required for different chronic conditions are similar. This reality led us to develop a middle-range theory of self-care of chronic illness to capture a more holistic view of those with one or multiple chronic conditions [3]. Since publication in 2012, the theory 
has already been widely cited and used in research, education, and clinical practice with patients experiencing a wide variety of chronic conditions (e.g., Parkinson's disease, psychosis, inflammatory bowel disease, diabetes, sickle cell disease, chronic obstructive pulmonary disease, coronary heart disease, hypertension, and childhood obesity) [4]. The instrument tested in this study reflects self-care as described in the middle-range theory.

\section{$\underline{\text { Availability of Instruments }}$}

No theory-based instruments exist to measure general, overall self-care or self-management as a process in which individuals engage to maintain health and manage illness. Most available general measures address barriers and facilitators of self-care. For example, the Patient Assessment of Self-management Tasks questionnaire (PAST) assesses to what extent patients feel they need to perform different self-management tasks in their daily lives and to what extent they feel a need for support with these tasks.[9] PAST measures four dimensions of tasks and support needs: 1) medical management; 2) communication with healthcare providers; 3) coping with the consequences of the illness; and 4) making lifestyle changes. Another instrument is the Appraisal of Self-Care Agency Scale-Revised (ASAS-R) in which self-care agency is defined as having three types of traits: foundational, operational and enabling; the 15-item ASAS-R measures having, developing, and lacking power for self-care [10]. Other available measures target patient assessment of chronic illness care [11], discrete self-care behaviors (e.g., medication adherence, weight loss, or physical activity levels), or self-efficacy for self-care [12]. To the best of our knowledge, this instrument is the first theoretically-based measure of the process of self-care that can be used in persons with multiple chronic conditions or in populations with a variety of different conditions.

\section{Instrument Development Methods}




\section{$\underline{\text { Item generation }}$}

The Middle Range Theory of Self-Care of Chronic Illness guided the choice of topics addressed in the instrument. The three theorists $(\mathrm{BR}, \mathrm{AS}, \mathrm{TJ})$ reviewed existing measures of self-care for specific illnesses, measures of specific behaviors, the Patient-Reported Outcomes Measurement Information System (PROMIS) measures (http://www.healthmeasures.net/explore-measurementsystems/promis), and clinical guidelines to identify potential items addressing the three major concepts of the theory. We generated 26 Self-Care Maintenance, 10 Self-Care Monitoring, and 18 Self-Care Management items for consideration.

Some were overlapping in content, others were conflicting (i.e., drink more liquids, drink fewer liquids), some items were condition-specific (e.g., use a soft toothbrush or water pik), and others were very general (e.g., eat 3 balanced meals each day). Over a 7-month period in 2013, the three theorists discussed, reviewed and revised multiple versions of the SC-CII. Areas that needed the most discussion were items related to physical activity, smoking, and stress management. It was difficult to formulate these items in a way that was congruent with existing evidence while still being applicable to a wide range of chronic conditions. For example, recommendations for exercise differ for people seeking to prevent disease (e.g., exercise 30 minutes a day) and those with heart failure. Changes made over that period included the wording of the directions, specific wording of items, and the response headers. Ten Self-Care Maintenance items, 6 Self-Care Monitoring items, and 4 Self-Care Management items were selected by consensus among the three theorists based on their potential to be applicable to multiple and varied chronic conditions and different cultural contexts. This 20 -item measure (SC-CII v.1) was considered ready for psychometric testing.

\section{$\underline{\text { Content Validity }}$}


Content validity refers to the degree to which an instrument includes an appropriate sample of items for the construct being measured [13]. Once items were generated based on careful conceptualization and domain analysis, content was evaluated by nurse experts in the field. Since the SC-CII was designed to measure self-care of chronic illness as defined in the Middle Range Theory [3], relevance of the proposed items was judged by a 5-member expert panel comprised of doctorally prepared nurse academics with expertise in chronic illness, theory, and in measurement. These content experts were asked to rate the content relevance of each item on a 4-point Likert scale ( 1 = 'not relevant' to 4 = 'very relevant'). The experts were also asked for suggested revisions and whether any important content was missing [14].

The Content Validity Index (CVI) was used to quantify content validity. The CVI was calculated for each individual item and for each scale. To be content valid, each item had to receive a score of 3 or 4 by four of five experts or .80 overall [15]. Items in the Self-Care Monitoring scale needed the most revision. After two rounds of content validity testing with the same five experts, the content validity of each individual item ranged from .8 (item \#7 in the Self-Care Maintenance scale: Avoid cigarettes and tobacco smoke?) to 1.00 (four separate items). The CVI for each scale was calculated as the proportion of items the experts rated as relevant [15]. The final CVI of the Self-Care Maintenance scale was .89, Self-Care Monitoring scale was .88, and CVI for the Self-Care Management scale was .96. Minor editing suggested by the expert panel was incorporated into the final instrument before patients were asked to complete it.

\section{Psychometric Testing Methods}

\section{$\underline{\text { Sample }}$}

We sought a sample size sufficient to conduct confirmatory factor analysis (CFA). Major 
textbooks advocate a number of approximately 200 as sufficient for this purpose,[16] but to assure a stable solution and protect against bias due to lack of statistical power, we enrolled a sample of 407 adults with chronic illness. Participants were enrolled from in-patient and outpatient settings in five sites in the eastern and southern United States. All participants were over age 18, able to read and write in English, cognitively intact, and had at least one chronic illness. No specific disease or disease stage was targeted for enrollment. No exclusion criteria were specified.

Institutional Review Board (IRB) approval for the ethical treatment of human subjects in the conduct of this study was obtained at each site. At the primary enrollment site, the University of Pennsylvania, we received approval for an exemption, the category used for research protocols that involve human subjects, but present little if any risk to the participants. Consistent with the Code of Federal Regulations, written informed consent was not required. Consent was assumed in anyone who completed the SC-CII after the study was explained. Most of the data were collected at this site. At other sites the SC-CII was obtained as part of another project and written informed consent was obtained.

Collaborators at urban and rural sites who were engaged in research invited patients with chronic illness to complete the SC-CII. Some collaborators enrolled patients in out-patient clinics and some, including the primary site, enrolled patients who were hospitalized. In addition, 19 volunteers from ResearchMatch.org responded to our online invitation to complete the SC-CII if they had a chronic illness. ResearchMatch.org is a national electronic, web-based registry with a large population of volunteers who have consented to be contacted by researchers about health studies. The U.S. National Institutes of Health supports this website as part of the Clinical Translational 
Science Award program. All data were collected between 2015 and 2016.

All participants completed the SC-CII v.2. For in-patients, research assistants (RA) typically visited medical-surgical units where people with a chronic illness were recovering. After referral by the patient's physician or nurse, the RA approached the patient, asked permission to describe the study, obtained consent, and administered the instrument along with the brief questionnaire addressing demographic and clinical information. Some were interviewed to obtain demographic and clinical information. Completion of surveys took approximately 10 minutes so the RA waited while the patient completed the surveys. Names were not placed on the completed form. At out-patient sites, patients were recruited through flyers posted at clinics. Interested individuals were referred to the collaborating investigator who then set up a time for data collection. Data were collected during a face-to-face interview. De-identified data were faxed or mailed to the central site. At one site, data on demographic and clinical data were gathered from patient administrative records but at other sites demographic and clinical data were collected directly from patients.

\section{$\underline{\text { Analysis }}$}

As dimensionality testing must precede reliability testing [17], we began with factor analysis and then assessed reliability. We conducted the factor analysis in Mplus 7.4 [18] using CFA since the instrument was theory-based. Factor loadings higher than $|.30|$ are considered adequate $[19,20]$. As several items had non-negligible positive kurtosis, we used the Robust Maximum Likelihood (MLR) method for parameters estimation. To examine model fit we used several goodness-of-fit indices: the Comparative Fit Index (CFI), the Tucker and Lewis Index (TLI), the Root Mean Square Error of Approximation (RMSEA), and the Standardized Root Mean Square Residual (SRMR) [21-23]. The CFI and the TLI are used to compare the model of interest with a null model [24], with values of .90-.95 indicating acceptable fit and values above .95 indicating good 
fit [25]. RMSEA is used to estimate lack of model fit, with values of $\leq .05$ indicating a wellfitting model, .05-.08 indicating a moderate fit, and $\geq .10$ indicating poor fit [26]. SRMR is a measure of fit in the sample, with values $\leq .08$ indicating good fit. Traditional chi-square statistics are reported; however, due to sensitivity of the chi-square likelihood ratio test to sample size, chi-square test results were not used in interpreting model fit. Scale reliability was estimated with Cronbach's alpha coefficients as well as with composite reliability [27] or omega coefficient [28], where values of 0.7 or above are considered adequate [29]. Items discrimination was estimated with item-total corrected correlation coefficients [30], where values of 0.3 or above are considered adequate [31]. Item difficulty analysis does not apply to items like those in our scales, since they do not distinguish between correct and wrong answers: however, the examination of items means and standard deviations was deemed to give information regarding the usefulness of items to provide the kind of information needed. In particular, with 5 point Likert-type items like those in our scales, the higher the variability of items, and the more the mean of the items is at the center point of the "theoretical" distribution, the better the item performance [32].

As part of the examination of the factorial structure of the instrument, we also tested a general model where all items and all three scales were analyzed with CFA. This analysis, in case of good fit, would further confirm the factorial validity of the scales coming from three separate confirmatory factor analyses.

\section{Results}

As shown in Table 1, the full sample of 407 was predominately Caucasian older adults with at least some college education. About one-third were employed full or part-time. Most reported an annual income sufficient to make ends meet. The average number of chronic conditions reported 
was 2.7; the most common conditions were diabetes, heart failure, hypertension, and arthritis.

\section{$\underline{\text { Self-Care Maintenance scale }}$}

Dimensionality. Self-Care Maintenance is described as comprising health promoting behavior and illness related behavior, which are measured respectively by 4 and 3 items (an eighth item is related to both dimensions). Thus, we first specified a two-factor confirmatory model. The goodness of fit indices of this model were very good: $\chi^{2}(18, \mathrm{~N}=407)=32.4, \mathrm{p}=.02, \mathrm{CFI}=$ $.94, \mathrm{TLI}=.91, \mathrm{RMSEA}=.044(90 \% \mathrm{CI}=.02-.069) \mathrm{p}=.62, \mathrm{SRMR}=.040($ Figure 1$)$. However, inspection of factor loadings revealed one item with factor loadings lower than .30. This item (\#7: How often do you avoid cigarettes and tobacco smoke, with options from never to always) had low correlations with all the other Self-Care Maintenance items, making this item an outlier in this data set [19]. Based on this result, Research Assistants (RAs) at the primary site performed two rounds of cognitive interviewing with individuals who met our inclusion criteria. Based on those interviews, we concluded that the original item was awkwardly worded and not clear to respondents. Thus, item \#7 was excluded from subsequent analyses, but revised and kept in the instrument pending further testing.

A second CFA model with the remaining seven items displayed a marginal fit to the data, with the misfit caused by allocation of item \#4 (eat a special diet) to health promoting behavior. Allocation of this item to this dimension of Self-Care Maintenance resulted in a significant modification index of 11.16. Reallocation of item \#4 to illness related behavior produced a model with an excellent fit to the data: $\chi^{2}(13, \mathrm{~N}=407)=19.55, \mathrm{p}=.11, \mathrm{CFI}=.97, \mathrm{TLI}=.95$, RMSEA $=.035(90 \% \mathrm{CI}=.00-.065) \mathrm{p}=.76, \mathrm{SRMR}=.036($ Table 2$)$. This successful reallocation suggested to us that patients change their diets because of an illness, not to prevent illness. All factor loadings were significant and the two factors were positively correlated at .50 . 
Scale Internal Coherence and Item Analysis. When the alpha coefficient was computed with the seven remaining items in the scale, a poor coefficient of .63 was obtained. However, alpha assumes that the items satisfy a unidimensional structure. Knowing that there are two facets represented in this scale, a more appropriate reliability coefficient that takes multidimensionality into account is the global reliability index for multidimensional scales [33]. This coefficient was better at .67, but still not adequate [31]. All items presented adequate discrimination, with item to total corrected correlation higher than .30. While items from the Health promoting behavior factor had adequate variability and a mean near the center of the theoretical distribution of 3 , items 2, 5 and 6 of Illness related behavior had less variability and higher means.

\section{$\underline{\text { Self-Care Monitoring scale }}$}

Dimensionality. We posited that a single factor would underlie the five items composing the Self-Care Monitoring scale so we specified a one-factor model CFA. This model had a partially adequate fit: $\chi^{2}(5, \mathrm{~N}=407)=31.3, \mathrm{p}<.01, \mathrm{CFI}=.94, \mathrm{TLI}=.87, \mathrm{RMSEA}=.11(90 \% \mathrm{CI}=.078-$ $.154) \mathrm{p}<.01, \mathrm{SRMR}=.039$. Inspection of the modification indices revealed that the misfit was caused by an excessive covariance between items \# 9 (monitor your condition) and \# 10 (pay attention to how you feel). The fact that these two similar items are next to each other in the instrument seems to have exacerbated the meaning that they share. That is, proximity increased the shared variance between the two items. Accordingly, when we re-ran the model allowing the residuals of these two items to be correlated $[34,35]$, the fit was almost perfect: $\chi^{2}(4, \mathrm{~N}=405)=$ 2.96, $\mathrm{p}=.56, \mathrm{CFI}=1.00, \mathrm{TLI}=1.01, \mathrm{RMSEA}=.00(90 \% \mathrm{CI}=.00-.066) \mathrm{p}=.87, \mathrm{SRMR}=.012$. All factor loadings were positive and significant, ranging from .53 to .88 (Table 2). The correlation between residuals from items \# 9 and \# 10 was .38 . The correlation between the model estimates with and without the residuals covariance was .99 , so this specification did not 
alter parameter estimates. The two items have been physically separated in the final version of the scale.

Scale Internal Coherence and Item Analysis. The alpha coefficient of the Self-Care Monitoring scale was .86. However, since the factor loadings are not all equal and since there is a covariance between two residuals, a more appropriate estimate of reliability is Raykov's composite reliability coefficient (Raykov, 2012), which was .81. Regardless of method used, the internal coherence of this scale was adequate. All items had adequate discrimination, with an item to total corrected correlation $>.30$. Items means were generally above the theoretical mean, and variability was around the observed mean except for items 9 and 10, which had higher means and lower SDs.

\section{$\underline{\text { Self-Care Management scale }}$}

Dimensionality. Self-Care Management is defined by the two facets of autonomous behavior and consulting behavior, with each facet measured by three items, with one additional item (\#14, how quickly did you recognize a symptom of your illness) postulated to be related to both facets. Thus, we first specified a two-factor confirmatory model. The goodness of fit indices of this model were adequate (except for the TLI): $\chi^{2}(12, \mathrm{~N}=251)=27.36, \mathrm{p}=.01, \mathrm{CFI}=.92$, TLI $=.87, \mathrm{RMSEA}=.071(90 \% \mathrm{CI}=.036-.14) \mathrm{p}=.14, \mathrm{SRMR}=.049$. An inspection of factor loadings revealed that item \#17 (take a medicine to make the symptom decrease or go away) of consulting behavior had a marginal but significant factor loading of .32. Another item \#14 (monitor for symptoms) loaded only on autonomous behaviour. The model was then respecified by fixing the cross loading of item \#14 at 0 , thus achieving a better fit: $\chi^{2}(13, N=251)=27.56$, $\mathrm{p}=.01, \mathrm{CFI}=.93, \mathrm{TLI}=.88, \mathrm{RMSEA}=.067(90 \% \mathrm{CI}=.031-.10) \mathrm{p}=.19, \mathrm{SRMR}=.048$. The final factor loadings are presented in Table 2 . The two factors were positively correlated at .51 . 
Scale Internal Coherence and Item Analysis. The Self-Care Management scale was intended to yield a single score. When the alpha coefficient was computed with the seven items in the scale, a marginal coefficient of .67 was obtained. As noted above, alpha assumes that the items reflect a unidimensional structure. Knowing that there are two facets represented in this scale, we used a more appropriate reliability coefficient that takes into account the multidimensionality of the scale, the global reliability index for multidimensional scales [33]. Reliability with this coefficient was .71, so use of a composite score for measuring Self-Care Management is psychometrically justified. All items had adequate discrimination, with item to total corrected correlation $>.30$. Item means were generally above the theoretical mean-point and variability was adequate, close to the observed mean, with the exception of item \#18, which had a higher mean and a lower SD.

\section{$\underline{\text { Simultaneous Confirmatory Factor Analysis }}$}

As a final step we conducted a simultaneous CFA on the combined set of items. CFA supported this more general model with the following fit indices: $\chi^{2}(141, \mathrm{~N}=251)=210, \mathrm{p}<.001, \mathrm{CFI}=$ $.93, \mathrm{TLI}=.91, \mathrm{RMSEA}=.044(90 \% \mathrm{CI}=.031-.056) \mathrm{p}=.77$, SRMR $=.051$. Factor loadings and factor correlations from this solution are displayed in table 3.

\section{$\underline{\text { Scoring }}$}

The final SC-CII version 2.0 includes 8 Self-Care Maintenance items, 6 Self-Care Monitoring items, and 6 Self-Care Management items. All items are rated on a 5-point ordinal response scale. The Self-Care Maintenance and Self-Care Monitoring scales asks: How often or routinely do you do the following? Responses range from never to always. The Self-Care Management scale asks: How likely are you to use one of these? Responses range from not likely to very 
likely. Two items in the Self-Care Management scale include a 0 option (i.e., I did not recognize the symptom; I did not do anything to manage symptoms).

Note that three separate scores are produced to sufficiently and adequately provide a measure of self-care. Each of the three scales (Self-Care Maintenance, Self-Care Monitoring, and Self-Care Management) is scored separately and standardized 0 to 100 with higher scores indicating better self-care, which negates potential issues with a different number of items in each scale. The scales are scored separately rather than being summed as a single measure of self-care primarily because individuals who do not have symptoms logically are unable to report how they manage their symptoms. In our early experience developing a measure of self-care for individuals with heart failure we discovered that missing data compromised study results.[36] Further, as patients became more adept at self-care they had fewer symptoms, but we were unable to capture that positive change with a composite score because of issues surrounding missing data. The SC-CII is freely available on our website: www.self-care-measures.com.

\section{Discussion}

The purpose of this study was to test the psychometric properties of the SC-CII, a new theorybased measure of self-care designed for use with individuals with chronic illness, regardless of the diagnosis. This initial psychometric testing is promising; item means are generally high, and researchers and clinicians are encouraged to use the SC-CII when they are interested in measuring self-care among those with chronic illness. Although disease specific measures may be more sensitive for the detection and quantification of small changes that are important to clinicians or patients [37], a generic instrument designed to measure self-care is anticipated to be valuable in populations with more than one chronic disease and useful in comparing self-care behaviors across different populations and interventions. 
Although the three sections in the scale were originally developed to cover the three dimensions of self-care (Self-Care Maintenance, Self-Care Monitoring, and Self-Care Management), theoretical facets of these dimensions were evident in factor analysis of both the Self-Care Maintenance and Self-Care Management scales. That is, in Self-Care Maintenance, there are items related to both health promoting behavior and illness related behavior. In other words, to improve well-being, to preserve health, or to maintain physical and emotional stability (Self-Care Maintenance), behaviors aimed at both promoting health (e.g. getting enough sleep) and dealing with illness (e.g. taking medication) contribute to this construct. We were interested to learn that eating a healthy diet was not a health promoting behavior but instead an illness related behavior in this sample. That is, people seem to view healthy eating as a necessity rather than a norm. This result reinforces the need to engage people in healthy eating early in life before food choices need to be modified because of an illness.

Reliability of the Self-Care Maintenance scale was barely adequate perhaps because of item \# 7 (avoid cigarettes and tobacco smoke). This item was problematic in initial development efforts, content validity testing, and in this analysis. We kept it because of the importance of the item and it has been reworded to ask "Do you avoid tobacco smoke?". This item was understandable to respondents in cognitive interviewing, so we will test this item in future psychometric testing. This scale was meant to yield a single score, not two different scores reflecting different facets of the construct. It is possible, however, to achieve this aim even when multidimensionality is evident. Bentler (2006) notes that "every multidimensional coefficient implies a particular composite with maximal unidimensional reliability" (p. 343), suggesting that although the dimensionality is complex, the final reliability estimates "can be interpreted to represent a unidimensional composite" [38] (p. 341). This approach has been used in previous studies, where 
a global score was recommended once internal coherence of a multidimensional scale was demonstrated with CFA [39].

The Self-Care Monitoring scale functioned well except for the need to allow the residuals of two items to be correlated. A minor revision has been made (changing the location of item 10), which we anticipate will resolve this issue in subsequent testing.

As theorized, factor analysis revealed that Self-Care Management had two facets of behavior that reflect the response to signs and symptoms when they occur (Self-Care Management): autonomous behavior and consulting behavior. Autonomous behaviors are those behaviors that people choose to do, innately or based on prior experience, when symptoms occur (e.g. changing activity level). Consulting behaviors are behaviors recommended by others such as talking to a health care provider in case of symptoms. Reliability was only adequate, probably because item \#17 (take a medicine to make the symptom decrease or go away) did not fit perfectly in consulting behavior. However, we suggest further testing before we revise it since that is also an extremely relevant self-care behavior. Not all patients recognize that taking a medicine is an option when symptoms occur because they may feel that it is inappropriate to change their prescribed medication without physician direction. Testing the scale in a larger and much more diverse sample is anticipated to provide us with more information on the value of this item for self-care in a broad population of patients with chronic illness.

Limitations of this study include an ethnically homogenous sample of primarily Caucasians living in the US with a high level of education. Most of the participants had cardiovascular diseases and a relatively low mean age. Most were recruited from urban communities. Further testing in a more diverse population is needed. As this is a patient-reported outcome, we intend 
to further our assessment of content validity with patients in the future as, at this time, content validity is only based on the comments of nurse experts. Further testing of hypotheses concerning relationships with other variables and change over time is also needed. Strengths of the study include the large sample size and the enrollment of patients from several large regional medical centers that draw patients from both urban and rural areas in the United States.

Although more testing is needed, we deliberately chose to share the development and psychometric testing of this new instrument with the scientific community so that further testing can be conducted by others. Testing of stability (test-retest reliability), responsiveness and cultural appropriateness are needed. We encourage others to use the scales and sharing data and experiences to optimize usefulness of the SC-CII. Although non-English speaking populations were excluded in this study, efforts are currently underway testing the SC-CII in the Netherlands, Sweden, and Italy.

\section{Conclusions}

Self-care is an essential element in the care of a chronic illness. The results of this study illustrate that the SC-CII is adequate in reliability and sufficiently valid to allow further testing. The SCCII fills an important gap in the literature and is anticipated to be useful in research aimed at understanding and improving self-care in the growing population of patients with chronic illness. 


\section{List of abbreviations}

Self-Care of Chronic Illness Inventory (SC-CII)

Appraisal of Self-Care Agency Scale-Revised (ASAS-R)

Patient-Reported Outcomes Measurement Information System (PROMIS)

Content Validity Index (CVI)

Confirmatory Factor Analysis (CFA)

Robust Maximum Likelihood (MLR)

Comparative Fit Index (CFI)

Tucker and Lewis Index (TLI)

Root Mean Square Error of Approximation (RMSEA)

Standardized Root Mean Square Residual (SRMR)

Research Assistants (RAs)

\section{Declarations}

The conduct of this study was approved by the appropriate Institutional Review Board at each data collection site. At some sites written consent was used, but at others verbal consent was deemed sufficient by the local Institutional Review Board. All subjects gave written or verbal informed consent to participate.

Consent for publication: not applicable Availability of data and material: The dataset analyzed for this article are available from the corresponding author.

Competing interests: None of the authors has financial or non-financial competing interests relevant to this publication.

Funding: The study was personally funded.

Authors' contributions: 
- Riegel: instrument development, data collection, analysis, manuscript preparation

- Barbaranelli: analysis, manuscript preparation

- Sethares: data collection, manuscript preparation

- Daus: data collection, manuscript preparation

- Moser: data collection, manuscript preparation

- Miller: data collection, manuscript preparation

- Haedtke: data collection, manuscript preparation

- Feinberg: data collection, manuscript preparation

- Lee: data collection, manuscript preparation

- Stromberg: instrument development, analysis, manuscript preparation

- Jaarsma: instrument development, analysis, manuscript preparation

Acknowledgements: We acknowledge the efforts of these individuals who assisted with data collection: Maureen Hogan, Allison Cameron, Rachel Giusti and Michaela Orsino 
$\underline{\text { References }}$

1. World Health Organisation: Noncommunicable diseases. In. Geneva, Switzerland; 2014.

2. Ausili D, Masotto M, Dall'Ora C, Salvini L, Di Mauro S: A literature review on selfcare of chronic illness: definition, assessment and related outcomes. Professioni infermieristiche 2014, 67(3):180-189.

3. Riegel B, Jaarsma T, Stromberg A: A middle-range theory of self-care of chronic illness. ANS Advances in nursing science 2012, 35(3):194-204.

4. Riegel B, Jaarsma T, Stromberg A: A Middle-Range Theory of Self-Care of Chronic Illness. In: Middle Range Theory for Nursing. 4th edn. Edited by Smith MJ, Liehr P. New York, NY: Springer Publishing Company; 2017.

5. Riegel B, Moser DK, Buck HG, Dickson VV, Dunbar SB, Lee CS, Lennie TA, Lindenfeld J, Mitchell JE, Treat-Jacobson DJ et al: Self-Care for the Prevention and Management of Cardiovascular Disease and Stroke: A Scientific Statement for Healthcare Professionals From the American Heart Association. $J$ Am Heart Assoc 2017, 6(9).

6. Buttorff C, Ruder T, Bauman M: Multiple Chronic Conditions in the United States. In. Santa Monica, CA; 2017.

7. Ward BW, Schiller JS: Prevalence of multiple chronic conditions among US adults: estimates from the National Health Interview Survey, 2010. Preventing chronic disease 2013, 10:E65.

8. Fortin M, Hudon C, Haggerty J, Akker M, Almirall J: Prevalence estimates of multimorbidity: a comparative study of two sources. BMC Health Serv Res 2010, 10:111.

9. van Houtum L, Rijken M, Heijmans M, Groenewegen P: Patient-perceived selfmanagement tasks and support needs of people with chronic illness: generic or disease specific? Ann Behav Med 2015, 49(2):221-229.

10. Sousa VD, Zauszniewski JA, Bergquist-Beringer S, Musil CM, Neese JB, Jaber AF: Reliability, validity and factor structure of the Appraisal of Self-Care Agency ScaleRevised (ASAS-R). Journal of evaluation in clinical practice 2010, 16(6):1031-1040.

11. Glasgow RE, Wagner EH, Schaefer J, Mahoney LD, Reid RJ, Greene SM: Development and validation of the Patient Assessment of Chronic Illness Care (PACIC). Medical care 2005, 43(5):436-444.

12. Ritter PL, Lorig K: The English and Spanish Self-Efficacy to Manage Chronic Disease Scale measures were validated using multiple studies. Journal of clinical epidemiology 2014, 67(11):1265-1273.

13. Polit DF, Beck CT: The content validity index: are you sure you know what's being reported? Critique and recommendations. Res Nurs Health 2006, 29(5):489-497.

14. Polit D, Beck C, Owen S: Is the CVI an acceptable indicator of content validity? Appraisal and recommendations. Res Nurs Health 2007, 30(4):459-467.

15. Lynn M: Determination and quantification of content validity. Nursing Research 1986, 35(6):382-385.

16. Kline RB: Principles and Practice of Structural Equation Modeling, 4th edn. New York, NY: Guilford Press; 2015.

17. Barbaranelli C, Lee CS, Vellone E, Riegel B: The problem with Cronbach's Alpha: comment on Sijtsma and van der Ark (2015). Nurs Res 2015, 64(2):140-145.

18. Muthén LK, \& Muthén, B. O. : Mplus User's Guide. Seventh Edition.; 1998-2014. 
19. Comrey AL, Lee HB: A first course in factor analysis, 2nd edn. Hillsdale, NJ: Erlbaum; 1992.

20. Tabachnick BG, Fidell LS: Using Multivariate Statistics, 5th edn. Boston, MA: Pearson Education, Inc.; 2007.

21. Byrne BM: Structural equation modeling with EQS: Basic concepts, applications, and programming, (2nd edition). Mahwah, NJ: Lawrence Erlbaum Associates, Inc.; 2006.

22. Meade AW, Johnson EC, Braddy PW: Power and sensitivity of alternative fit indices in tests of measurement invariance. Journal of Applied Psychology 2008, 93(3):568.

23. Vandenberg RJ, Lance $\mathrm{CE}$ : A review and synthesis of the measurement invariance literature: Suggestions, practices, and recommendations for organizational research. Organizational research methods 2000, 3(1):4-70.

24. Bentler PM: Comparative fit indexes in structural models. Psychological Bulletin 1990, 107:238-246.

25. $\mathrm{Hu}$ L, Bentler PM: Cutoff criteria for fit indexes in covariance structure analysis: Conventional criteria versus new alternatives. Structural Equation Modeling 1999, 6:1-55.

26. Browne MW, Cudek R: Alternative ways of assessing model fit. In: Testing structural equation models. edn. Edited by Bollen KA, Long JS. Newbury Park, CA: Sage; 1993: 136-162.

27. Fornell C, Larcker, D.: Evaluating Structural Equation Models with Unobservable Variable and Measurement Error. . Journal of Marketing Research 1981, 18:39-50.

28. McDonald RP: Test theory. A unified treatment.; 1999.

29. Bagozzi RP, Yi Y: Specification, evaluation, and interpretation of structural equation models. $J$ Acad Market Sci 2012, 40(1):8-34.

30. Crocker L, Algina J: Introduction to classical and modern test theory. Orlando, FL: Holt, Rinehart and Winston, Inc.; 1986.

31. Nunnally J, Bernstein IH: Psychometric theory. New York: McGraw Hill, Inc; 1994.

32. Kline T: Psychological testing: A practical approach to design and evaluation. Thousand Oaks, CA: Sage Publications, Inc.; 2005.

33. Raykov T: Scale Construction and Development Using Structural Equation Modeling. New York: The Guilford Press; 2013.

34. Bagozzi RP: Issues in the Application of Covariance Structure Analysis: A Further Comment. . J Consum Res 1983, 9:449-450.

35. Fornell C: Issues in the Application of Covariance Structure Analysis: A Comment. $J$ Consum Res 1983, 9:443-448.

36. Riegel B, Lee CS, Dickson VV, Carlson B: An update on the self-care of heart failure index. J Cardiovasc Nurs 2009, 24(6):485-497.

37. Guyatt GH, Bombardier $\mathrm{C}$, Tugwell PX: Measuring disease-specific quality of life in clinical trials. CMAJ 1986, 134(8):889-895.

38. Bentler PM: EQS 6 structural equations program manual. Encino, CA: Multivariate Software, Inc.; 2006.

39. Barbaranelli C, Lee CS, Vellone E, Riegel B: Dimensionality and reliability of the selfcare of heart failure index scales: further evidence from confirmatory factor analysis. Res Nurs Health 2014, 37(6):524-537. 
Table 1. Sociodemographic and Clinical Characteristics of the Sample of 407

\begin{tabular}{|c|c|c|c|}
\hline Sociodemographic Characteristics & Mean & SD & $\mathrm{n}$ \\
\hline Age & \multicolumn{2}{|c|}{$62.94 \pm 15$} & 399 \\
\hline & $\mathrm{N}$ & $\%$ & \\
\hline Male & 220 & 54.5 & 399 \\
\hline \multicolumn{4}{|l|}{ Race } \\
\hline Black/African American & 34 & 8.4 & \\
\hline White/Caucasian & 354 & 87.2 & \\
\hline Asian & 3 & .7 & \\
\hline Other (e.g., Native American) & 15 & 3.7 & \\
\hline Marital Status & & & 352 \\
\hline Single, never married & 53 & 15.1 & \\
\hline Married or partnered & 239 & 67.9 & \\
\hline Divorced, separated, or widowed & 60 & 17.0 & \\
\hline Education & & & 406 \\
\hline Less than high school graduate & 44 & 10.8 & \\
\hline High School Graduate & 122 & 30.1 & \\
\hline Some College & 99 & 24.4 & \\
\hline College Educated & 141 & 34.7 & \\
\hline Employment Status & & & 353 \\
\hline Full or part time & 131 & 37.1 & \\
\hline Income & & & 334 \\
\hline Comfortable; have more than enough to make ends meet & 106 & 31.7 & \\
\hline Have enough to make ends meet & 165 & 49.4 & \\
\hline Do not have enough to make ends meet & 63 & 18.9 & \\
\hline
\end{tabular}

\begin{tabular}{lcc}
\hline Clinical Characteristics & Mean & SD \\
\hline Total number of conditions & \multicolumn{2}{c}{$2.7 \pm 1.34$} \\
& $\mathrm{~N}$ & $\%$ \\
Heart Failure & 191 & 46.9 \\
Diabetes & 242 & 59.5 \\
Hypertension & 251 & 61.7 \\
Neurological Disorder (stroke, paralysis, dementia) & 34 & 8.4 \\
Pulmonary Disease (asthma, emphysema, lung disease) & 50 & 12.3 \\
Kidney Disease & 48 & 11.8 \\
Arthritis & 122 & 30.0 \\
Other (e.g. gastrointestinal disease, arrhythmia) & 34 & 8.3 \\
\hline
\end{tabular}


Table 2. Factor loadings, item-total corrected correlation, means and standard deviations of Individual Items in the Self-Care of Chronic Illness Inventory

\begin{tabular}{|l|c|c|c|c|}
\hline \multicolumn{5}{|l|}{ Self-Care Maintenance } \\
\hline Health promoting behavior & Loading & $I T C$ & $M$ & $S D$ \\
\hline 1. Make sure to get enough sleep? & .648 & .39 & 3.80 & .99 \\
\hline $\begin{array}{l}\text { 3. Do physical activity (e.g. take a brisk walk, use the } \\
\text { stairs)? }\end{array}$ & .366 & .31 & 3.30 & 1.20 \\
\hline $\begin{array}{l}\text { 8. Do something to relieve stress (e.g., medication, } \\
\text { yoga, music)? }\end{array}$ & .685 & .36 & 3.55 & 1.02 \\
\hline Illness related behavior & & & & \\
\hline $\begin{array}{l}\text { 2. Try to avoid getting sick (e.g., flu shot, wash your } \\
\text { hands)? }\end{array}$ & .399 & .30 & 4.64 & .69 \\
\hline 4. Eat a special diet? & .379 & .34 & 3.32 & 1.18 \\
\hline 5. See your healthcare provider for routine health care? & .631 & .36 & 4.56 & .86 \\
\hline 6. Take prescribed medicines without missing a dose? & .665 & .42 & 4.67 & .69 \\
\hline
\end{tabular}

\begin{tabular}{|l|c|c|c|c|}
\hline \multicolumn{5}{|c|}{ Self-Care Monitoring } \\
\hline Health promoting behavior & Loading & $I T C$ & $M$ & $S D$ \\
\hline 9. Monitor your condition? & .583 & .60 & 4.26 & .94 \\
\hline 10. Pay attention to changes in how you feel? & .701 & .70 & 4.36 & .85 \\
\hline 11. Monitor for medication side-effects? & .725 & .66 & 4.08 & 1.15 \\
\hline $\begin{array}{l}\text { 12. Monitor whether you tire more than usual doing } \\
\text { normal activities? }\end{array}$ & .743 & .66 & 4.11 & .96 \\
\hline 13. Monitor for symptoms? & .874 & .76 & 4.15 & .98 \\
\hline
\end{tabular}

\begin{tabular}{|l|c|c|c|c|}
\hline \multicolumn{5}{|c|}{ Self-Care Management } \\
\hline Autonomous behavior & Loading & $I T C$ & $M$ & $S D$ \\
\hline $\begin{array}{l}\text { 14. If you had symptoms in the past month, how quickly } \\
\text { did you recognize it as a symptom of your illness? }\end{array}$ & .443 & .33 & 3.65 & 1.27 \\
\hline $\begin{array}{l}\text { 15. Change what you eat or drink to make the symptom } \\
\text { decrease or go away? }\end{array}$ & .674 & .47 & 3.86 & 1.19 \\
\hline 16. Change your activity level (e.g. slow down, rest)? & .492 & .39 & 4.01 & 1.05 \\
\hline 20. Did the treatment you used make you feel better? & .554 & .39 & 3.44 & 1.42 \\
\hline Consulting behavior & & & & \\
\hline $\begin{array}{l}\text { 17. Take a medicine to make the symptom decrease or } \\
\text { go away? }\end{array}$ & .317 & .28 & 3.83 & 1.27 \\
\hline $\begin{array}{l}\text { 18. Tell your healthcare provider about the symptom at } \\
\text { the next office visit? }\end{array}$ & .709 & .43 & 4.35 & 1.01 \\
\hline 19. Call your healthcare provider for guidance? & .719 & .41 & 3.48 & 1.40 \\
\hline
\end{tabular}

Note. Loadings come from Mplus completely standardized solutions and are all statistically significant ( $\mathrm{p}<.05$ or below) except where noted. item \#7 was excluded from analyses, as explained in the text. ITC $=$ Corrected item total correlation, $\mathrm{M}=$ Mean, $\mathrm{SD}=\mathrm{Standard}$ Deviation. 
Table 3. Factor loadings and Factor correlation from the simultaneous CFA

\begin{tabular}{lccr}
\hline \multicolumn{5}{c}{ Self-Care Maintenance } \\
Health promoting behavior & Illness related behavior \\
SCCII_1 & 0.692 & SCCII_2 & 0.554 \\
SCCII_3 & 0.286 & SCCII_5 & 0.527 \\
SCCII_8 & 0.567 & SCCII_6 & 0.493 \\
\multicolumn{5}{c}{ SCCII_4 } & 0.507 \\
SCCII_9 & 0.526 & Self-Care Monitoring & \\
SCCII_10 & 0.710 & & \\
SCCII_11 & 0.733 & & \\
SCCII_12 & 0.691 & & \\
SCCII_13 & 0.851 & & \\
\multicolumn{5}{c}{} \\
\multicolumn{5}{c}{ Self-Care Management } \\
Autonomous & behavior & Consulting behavior \\
SCCII_15 & 0.627 & SCCII_17 & 0.298 \\
SCCII_16 & 0.522 & SCCII_18 & 0.758 \\
SCCII_20 & 0.552 & SCCII_19 & 0.681 \\
SCCII14B & 0.460 & &
\end{tabular}

\section{Factor correlations}

\begin{tabular}{lcccc} 
& $\begin{array}{c}\text { Illness } \\
\text { related } \\
\text { behavior }\end{array}$ & $\begin{array}{c}\text { Self-Care } \\
\text { Monitoring }\end{array}$ & $\begin{array}{c}\text { Autonomous } \\
\text { behavior }\end{array}$ & $\begin{array}{c}\text { Consulting } \\
\text { behavior }\end{array}$ \\
\hline $\begin{array}{l}\text { Health promoting } \\
\text { behavior }\end{array}$ & 0.638 & 0.468 & 0.433 & 0.407 \\
Illness related behavior & & 0.715 & 0.619 & 0.553 \\
Self-Care Monitoring & & & 0.571 & 0.603 \\
Autonomous behavior & & & & 0.517 \\
\hline
\end{tabular}

Note. Results come from Mplus completely standardized solutions. All coefficients are statistically significant $(\mathrm{p}<.05)$. 
Figure 1. Graphic representation of the factor solutions derived from separate Confirmatory Factor Analyses

\section{Self-Care Maintenance}

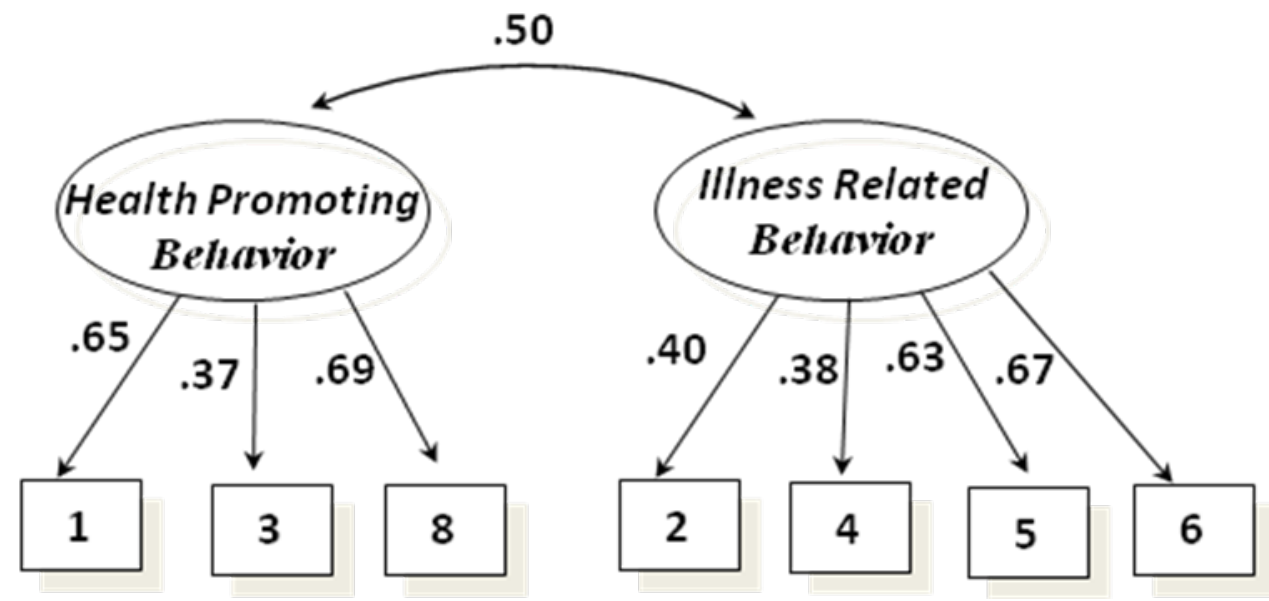

Self-Care Monitoring

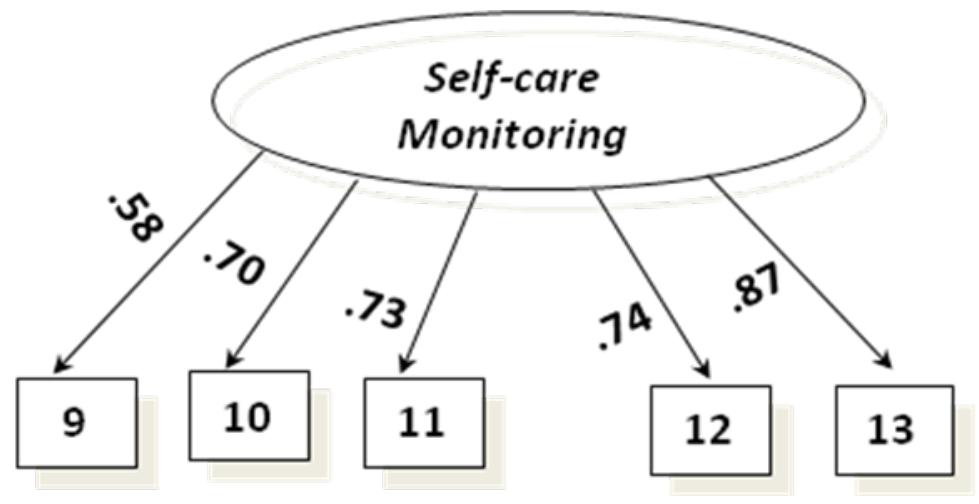

Self-Care Management

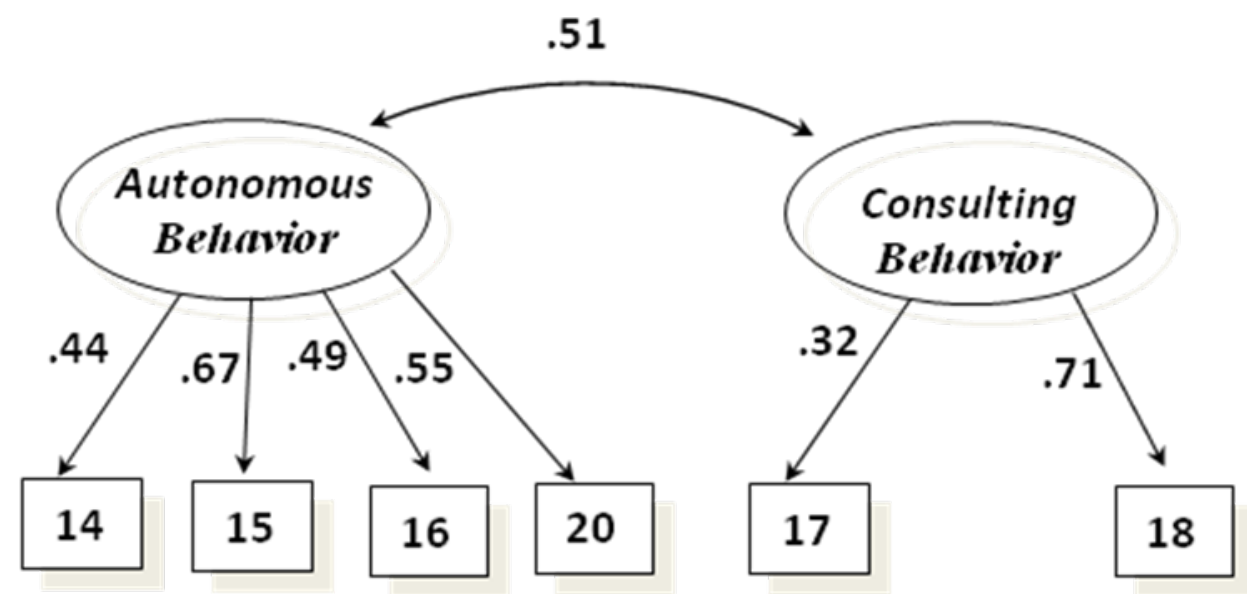

